OPEN ACCESS

Edited by:

Grigorios Korosoglou, GRN Klinik Weinheim, Germany

Reviewed by: Mariya Kronlage, Heidelberg University Hospital, Germany

Sorin Giusca,

GRN Klinik Weinheim, Germany

*Correspondence:

Grégoire Détriche gregoire.detriche@aphp.fr

†These authors have contributed equally to this work

Specialty section: This article was submitted to Atherosclerosis and Vascular Medicine,

a section of the journal Frontiers in Cardiovascular Medicine

Received: 29 November 2021 Accepted: 17 January 2022 Published: 07 February 2022

Citation:

Détriché G, Guédon A, Mohamedi N, Sellami O, Cheng C, Galloula $A$, Goudot G, Khider L, Mortelette H, Sitruk J, Gendron N, Sapoval M, Julia P, Smadja DM, Mirault T and Messas E (2022) Women Specific

Characteristics and 1-Year Outcome Among Patients Hospitalized for

Peripheral Artery Disease: A Monocentric Cohort Analysis in a Tertiary Center.

Front. Cardiovasc. Med. 9:824466.

doi: 10.3389/fcvm.2022.824466

\section{Women Specific Characteristics and 1-Year Outcome Among Patients Hospitalized for Peripheral Artery Disease: A Monocentric Cohort Analysis in a Tertiary Center}

\author{
Grégoire Détriché ${ }^{1,2,3 *}$, Alexis Guédon ${ }^{1}$, Nassim Mohamedi ${ }^{1}$, Olfa Sellami ${ }^{1}$, \\ Charles Cheng ${ }^{1}$, Alexandre Galloula ${ }^{1}$, Guillaume Goudot ${ }^{1,4}$, Lina Khider ${ }^{1,2,3}$, \\ Hélène Mortelette ${ }^{1}$, Jonas Sitruk ${ }^{1}$, Nicolas Gendron ${ }^{2,3,5}$, Marc Sapoval ${ }^{4,6}$, Pierre Julia ${ }^{4,7}$, \\ David M. Smadja ${ }^{2,3,5}$, Tristan Mirault ${ }^{1,2,3,4 \dagger}$ and Emmanuel Messas ${ }^{1,4 \dagger}$

\begin{abstract}
${ }^{1}$ Vascular Medicine Department, Hôpital Europeen Georges-Pompidou, Assistance Publique Hôpitaux de Paris, Université de Paris (APHP-CUP), Paris, France, ${ }^{2}$ Université de Paris, Innovative Therapies in Haemostasis, INSERM, Paris, France, ${ }^{3}$ Biosurgical Research Lab (Carpentier Foundation), Assistance Publique Hôpitaux de Paris, Centre-Université de Paris (APHP-CUP), Paris, France, ${ }^{4}$ Université de Paris, Paris Research Cardiovascular Center (PARCC), INSERM U970, Paris, France, ${ }^{5}$ Hematology Department, Hôpital Europeen Georges-Pompidou, Assistance Publique Hôpitaux de Paris, Université de Paris (APHP-CUP), Paris, France, ${ }^{6}$ Interventional Radiology Department, Hôpital Europeen Georges-Pompidou, Assistance Publique Hôpitaux de Paris, Universit de Paris (APHP-CUP), Paris, France, ${ }^{7}$ Vascular Surgery Department, Hôpital Europeen Georges-Pompidou, Assistance Publique Hôpitaux de Paris, Université de Paris (APHP-CUP), Paris, France
\end{abstract}

Although women have lower age-standardized cardiovascular disease incidence, prevalence, and death-related rates than men, there are also reports indicating that women with cardiovascular disease receive less care, fewer investigations, and have poorer outcomes after a coronary event. The aims of this study were to compare the characteristics of men and women hospitalized for peripheral artery disease (PAD), their cardiovascular and limb outcomes, and their 1-year mortality. The study is a prospective registry collecting data about all consecutive patients hospitalized for PAD within the vascular department of the tertiary center Georges-Pompidou European Hospital (Paris, France). Patients were required to have one of three inclusion criteria: previous revascularization of the lower limb or any lower limb artery occlusion due to an atherosclerotic vascular disease or hemodynamic evidence of PAD. Exclusion criteria were patients with lower extremity arterial occlusion due to another cause. All patients were followed-up for at least 12 months after the initial hospitalization. Among the 235 patients included, there were 61 women (26\%), older than men with a median age of 75.6 and 68.3 years, respectively. Main cardiovascular risk factors and comorbidities were similar for men and women except more former or current smokers [145 (83.4\%) vs. $33(54.1 \%)]$ and more history of coronary heart disease [42 (24.1\%) vs. 7 (11.5\%)] in men. Most patients [138 (58.8\%)] had critical limb ischemia and 97 (41.3\%) had claudication, with no difference for sex. After discharge, 218 patients received an antithrombotic therapy (93.2\%), 195 a lipid-lowering drug (83.3\%), 185 an angiotensin converting enzyme inhibitor or angiotensin-receptor blocker (78.9\%), similarly between sex. At 1-year, overall mortality, major adverse cardiovascular events, major adverse limb 
events did not differ with 23 (13.2\%), 11 (6.3\%) and 32 (18.4\%) in men, and 8 (13.1\%), 3 (4.9\%), 15 (24.6\%) in women, respectively, despite the difference in age. Overall mortality, cardiovascular outcomes, limb revascularization or amputation did not differ between men and women, 1-year after hospitalization for PAD although the latter were older, less smoker and had less coronary artery disease. Due to the small size of this cohort, larger studies and future research are needed to better understand sex-specific mechanisms in the pathophysiology and natural history of PAD.

Keywords: peripheral arterial disease, cardiovascular disease, sex differences, vascular surgical procedure, lower extremity arterial disease

\section{INTRODUCTION}

"Despite being responsible for causing $35 \%$ of deaths in women each year, cardiovascular disease in women remains understudied, under-recognized, and under-treated, with women under-represented in clinical trials" stated The Lancet women and cardiovascular disease Commission in May 2021 (1). Although women have lower age-standardized cardiovascular disease incidence, prevalence, and death rates than men (2) there are also reports indicating that women with cardiovascular disease receive less care, fewer investigations, and have poorer outcomes after a coronary event (3-6). The lower extremity arterial disease, also known as peripheral artery disease (PAD) in some extent, is the manifestation of the atherosclerotic cardiovascular disease (ASCVD) at the lower limbs level (7). Most patients presenting with asymptomatic PAD do not have a clinical history of cardiac or cerebral ischemic events, although they are at high risk for stroke, myocardial infarction and cardiovascular death $(8,9)$ with a 10 -year cardiovascular mortality of $18.7 \%$ in men and $12.6 \%$ in women with a low anklebrachial index $(\leq 0.90)(10)$. Sex difference in symptomatic PAD has been scantly studied and women may be less likely to undergo revascularization than men and more likely under-treated (1, 6, 11-13).

The aims of this study were to compare the characteristics of patients hospitalized for PAD, their cardiovascular and limb outcomes, and their mortality at 1 year according to sex.

\section{MATERIALS AND METHODS}

\section{Study Design}

The study is a prospective monocentric registry collecting exhaustive data about all patients consecutively hospitalized for PAD within the Georges-Pompidou European Hospital vascular department (APHP-Université de Paris). The methodology of the registry has already been published elsewhere (14). The protocol was approved by the local ethics committee (IRB CPP Sud Ouest et outre mer II 0702108 ) and patients provided written informed consent before enrollment. The data were retrieved from the patient's computerized record. We collected demographic, clinical, laboratory and imaging data as well as all the complications that had occurred for each patient followed.

\section{Study Population}

Eligible patients were at least 18 years of age and hospitalized for symptomatic lower extremity artery disease. Patients were required to have one of three inclusion criteria: previous revascularization of the lower limb or any lower limb artery occlusion due to an ASCVD or hemodynamic evidence of PAD as evidenced by an ankle-brachial index (ABI) of 0.90 or less or a toe-brachial index (TBI) of 0.60 or less, in accordance with current guidelines $(7,15)$. Exclusion criteria were patients with lower extremity arterial occlusion due to another cause than ASCVD.

All patients were followed-up for at least 12 months after the initial hospitalization. Patient care was provided according to the usual practice, without any change in management strategy. Phone contacts with the patients or their physicians have been performed when required. The primary end point was all cause mortality within 1 year. Registrar's offices have been consulted when required. Secondary end points were the occurrence of any event in the composite of cardiovascular death, myocardial infarction, or ischemic stroke defined as major adverse cardiovascular event (MACE), the occurrence of any event in the composite of lower limb major amputation or revascularization defined as major adverse limb event (MALE), or the occurrence of cancer.

\section{Statistical Analysis}

Discrete variables are presented as number and percentage, and continuous variables as median and interquartile range (IQR, 25th-75th percentile). Comparisons were made using chisquare test (or Fisher exact tests, when appropriate) for discrete variables, and Mann-Whitney test for continuous variables. All subsequent $p$-values are reported for 2 -tailed tests with a $5 \%$ threshold. Overall survival, MACE and MALE were calculated using the Kaplan-Meier method, and the values were compared using the log-rank test. All analyses were performed using SPSS software vs. 13.0 (SPSS Inc., Chicago, IL) and GraphPad Prism 5 (GraphPad Software, Inc., La Jolla, CA, USA).

\section{RESULTS}

\section{Cohort and Baseline Characteristics}

From January 2018 to January 2019 a total of 235 patients were included. Table 1 shows the characteristics of the patients. The median age was $70.0(59.3-79.8)$ years. There were $61(26 \%)$ 
TABLE 1 | Baseline characteristics and sex comparison.

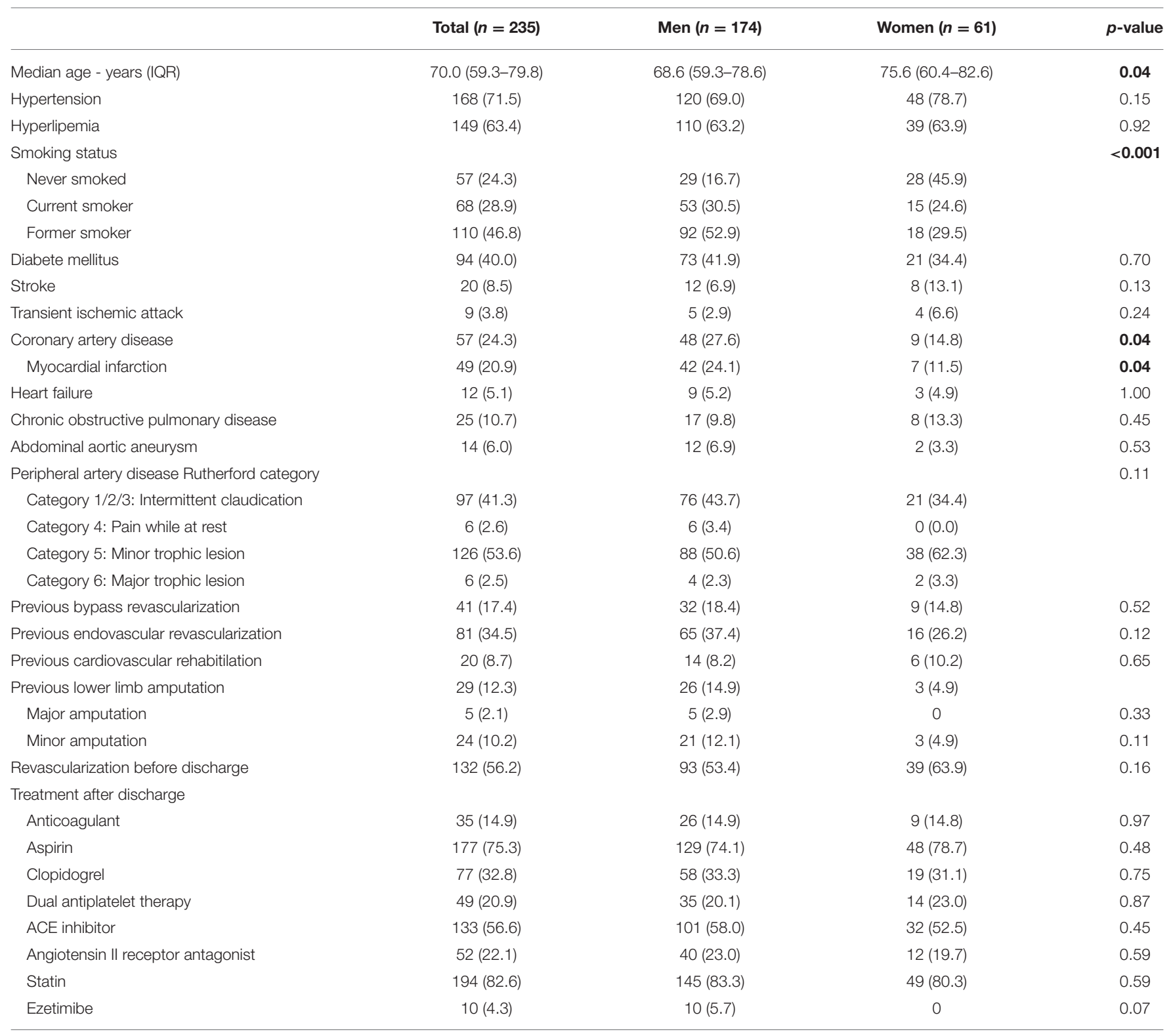

$I Q R$, interquartile range (25th - 75th percentile); $A C E$, angiotensin converting enzyme. Significant $p$ values are in bold.

women. They were older than men, with a median age of $75.6(60.4-82.6)$ and $68.3(59.3-78.6)$ years, respectively $(p=$ $0.04)$. Main cardiovascular risk factors were similar in both sex, with a trend for more hypertension in women $(78.7 \%, p=$ $0.15)$ and diabetes mellitus in men $(41.9 \%, p=0.70)$. However, tobacco use was significantly different with more former or current smokers in men $(p<0.001)$. In parallel, a history of coronary heart disease, and myocardial infarction in particular, was significantly higher in men [42 men (24.1\%) vs. 7 women (11.5\%), $p=0.04]$. Other comorbidities reflected the clinical complexity of the patients with $12(5.1 \%)$ patients with heart failure, $29(12.3 \%)$ with stroke or transient ischemic attack, and $25(10.7 \%)$ with chronic obstructive pulmonary disease. The majority of patients, 138 (58.8\%) had critical limb ischemia defined as pain of the lower limb while at rest or tissue loss and 97 (41.3\%) had claudication. Neither the PAD Rutherford category nor previous revascularizations differed between sex. Patients already had a history of vascular revascularization of the lower limbs with bypass for 41 (17.4\%) patients and endovascular procedure for $81(34.5 \%)$ patients. Already 29 (12.3\%) patients had previous amputation. Half of the patients has undergone a revascularization before discharge. After discharge, 218 patients received an antithrombotic therapy (93.2\%), 195 a lipidlowering drug (83.3\%), 185 an angiotensin converting enzyme inhibitor or angiotensin-receptor blocker (78.9\%), similarly between sex. 
TABLE 2 | One-year outcomes.

\begin{tabular}{|c|c|c|c|c|}
\hline & Total $(n=235)$ & Men $(n=174)$ & Women $(n=61)$ & $p$-value \\
\hline Death & $31(13.2)$ & $23(13.2)$ & $8(13.1)$ & 0.98 \\
\hline Median time to death - days (IQR) & $148(49-298))$ & $148(51-298)$ & $171(26-304)$ & 0.75 \\
\hline Cardiovascular death & $7(3.0)$ & $5(2.9)$ & 2 (3.3) & \\
\hline Sepsis & $8(3.4)$ & $5(2.9)$ & $3(4.9)$ & \\
\hline Unknown & $11(4.7)$ & $9(5.2)$ & 2 (3.3) & \\
\hline Cancer & $11(4.7)$ & $8(4.6)$ & $3(4.9)$ & 1.00 \\
\hline MACE & $14(6.0)$ & $11(6.3)$ & $3(4.9)$ & 1.00 \\
\hline Median time to MACE - days (IQR) & $107(34-163)$ & $128(44-190)$ & $21(14-87)$ & 0.19 \\
\hline Myocardial infarction & $10(4.3)$ & $10(5.7)$ & $0(0.0)$ & 0.07 \\
\hline Revascularization & $45(19.1)$ & $31(17.8)$ & $14(23.0)$ & 0.38 \\
\hline Bypass procedures & $16(6.8)$ & $12(6.9)$ & $4(6.6)$ & \\
\hline Aorto-iliac & $2(0.9)$ & $2(1.1)$ & $0(0)$ & \\
\hline Femoro-popliteal & $11(4.7)$ & $7(4.0)$ & $4(6.6)$ & \\
\hline Bellow the knee & $3(1.3)$ & $3(1.7)$ & $0(0)$ & \\
\hline Endovascular procedures & $44(18.7)$ & $34(19.5)$ & $10(16.4)$ & \\
\hline Aorto-iliac & $8(3.4)$ & $7(4.0)$ & $1(1.6)$ & \\
\hline Femoro-popliteal & $26(11.1)$ & $19(10.9)$ & $7(11.5)$ & \\
\hline Bellow the knee & $10(4.3)$ & $8(4.6)$ & 2 (3.3) & \\
\hline Major amputation & $5(2.1)$ & $3(1.7)$ & $2(3.3)$ & 0.61 \\
\hline Minor amputation & $13(5.5)$ & $10(5.7)$ & $3(4.9)$ & 1.00 \\
\hline
\end{tabular}

IQR, interquartile range (25th - 75th percentile); MACE, major adverse cardiovascular event; MALE, major adverse limb event. Figures in italic correspond to procedures and not patients.

\section{One-Year Outcomes}

At 1 year, overall survival, MACE or MALE did not differ between sex, with 23 (13.2\%), $11(6.3 \%)$, and $32(18.4 \%)$ in men, and 8 (13.1\%), 3 (4.9\%), 15 (24.6\%) in women, respectively (Table 2). Sepsis and cardiovascular events were the leading cause of death. Cancer annual incidence was 5\%. Although nonstatistically significant, MACE affected more men [11 (6.3\%) men vs. 3 (4.9\%) women], especially myocardial infarction, whereas it was the contrary for MALE affecting more women [15 (24.6\%) men vs. 32 (18.4\%) women], especially within the first 90 days (Figure 1). In patients with intermittent claudication (Rutherford category 1, 2, or 3) or critical limb ischemia (Rutherford category 4, 5, or 6) overall survival, MACE and MALE were similar between sex (Figure 2). Distribution of the level of revascularization was similar between men and women. Major amputation occurred in $3(1.7 \%)$ men and 2 (3.3\%) women, and minor amputations in 10 (5.7\%) men and 3 (4.9\%) women. When focusing on characteristics at inclusion on patients who died within 1 year, women were older than men with a median age of $87.6(80.1-92.3)$ and 76.2 years $(69.2-81.9)$ respectively $(p=0.02)$ and had more frequently a stroke in their past-medical history $3(37.5 \%)$ vs. 1 (4.3\%) for men $(p=0.04)$ (Table 3).

\section{DISCUSSION}

In this study, we found that among patients hospitalized for $\mathrm{PAD}$, women were older than men. However, there was no sex difference in overall mortality after 1 year of follow-up. Women smoked less and had less coronary artery disease, and we noticed a trend for fewer MACE and increased MALE vs. men. These data are consistent with the literature, where large studies observed that ASCVD outcomes were not higher in women compared with men (5).

Our study aimed at comparing characteristics and outcomes of patients hospitalized for PAD according to sex provides several key points. We did not find that women were undertreated or less likely to undergo revascularization than men $(1,6,11,12)$. Same rate of revascularization was observed in both men and women with even a trend to more procedures in women, but without any difference according to the level of limb revascularization $(16,17)$. Currently, the guidelines for symptomatic PAD recommend long-term treatments with at least antiplatelet agent and statin (7) to improve prognosis (18). Previous reports showed that this optimized therapy was less prescribed in women, suggesting a decrease in secondary prevention strategies in women compared to men (19). In our 
study, optimized therapy was approaching $80 \%$ of the patients whatever the sex. However, not all patients received statin at discharge. Forty patients (16.7\%) patients either presented a previous intolerance or refused to take statin or ezetimibe. Our data are in accordance with large recent therapeutic trials. In the COMPASS trial (9), lipid-lowering therapy was present in 82.8 to $83.8 \%$ of the patients, and 73.0 to $73.7 \%$ in the EUCLID trial (8). No patient from this cohort had a PCSK9 inhibitor. This new lipid lowering class has been approved for reimbursement in France since 2020 only, when the LDL cholesterol goal is not achieved and in combination with a statin. The clinical presentation of the patients in this study was more severe than most of PAD cohorts (20-22) with almost $60 \%$ presenting with critical limb ischemia. Outpatients were not included in that study indeed, as a consequence, revascularizations for intermittent claudication were under-represented. Although intermittent claudication is considered a hallmark manifestation of PAD, women are more than twice as likely as men to report the presence of atypical exertional leg symptoms that sometimes began at rest or no symptoms at all $(23,24)$. Other associated comorbidities, such as osteoarthritis or osteoporosis, may also delay the diagnosis of PAD in women (25). Therefore, women have probably a long "latent phase" in which ASCVD and PAD progresses leading to more revascularization when hospitalized. This may explain why we observed that women presented with more tissue loss and less intermittent claudication as already reported (26). Interestingly, despite an increased age and the severe clinical presentation, the 1 year amputation-free survival was similar in both men and women $(12,27)$.

Women were older than men with almost 10 years apart when they presented with PAD in our study (28). One explanation may come from the fact that men were more current and former smokers than women, and would have develop PAD at younger age, as smoking, the most powerful contributor to PAD, increases the risk by 2 to $3(29,30)$. But another explanation may relate to the preponderant role that estrogens play in women, as reported decades ago in the Framingham study. Women in pre-menopause developed less coronary artery disease than women in post-menopause or women of same age with early menopause after ovariectomy indeed (31). Since, protective cardiovascular effects of estrogens have been demonstrated (32). They promote arterial vasodilation, decrease action of pro-inflammatory cytokines, lower low density lipoproteins and increase high density lipoproteins (32, 33). The drop in estrogen at menopause gives way to the development of ASCVD. But the impact of gonadotropins shall not be underestimated as secretion of follicle-stimulating hormone (FSH) from the pituitary gland begins to rise above normal levels before menopause, when estrogen levels are still normal, and become high after menopause responsible for a decrease of estrogen levels $(34,35)$. FSH levels were found to be correlated with the coronary calcium score and carotid intima-media thickness in women (36). Women with a lower increase in FSH during their transition to menopause may be less at risk of atherosclerosis than those with a medium or high increase in FSH at the same period $(37,38)$. Our team recently assessed the impact of gonadotropins in vitro

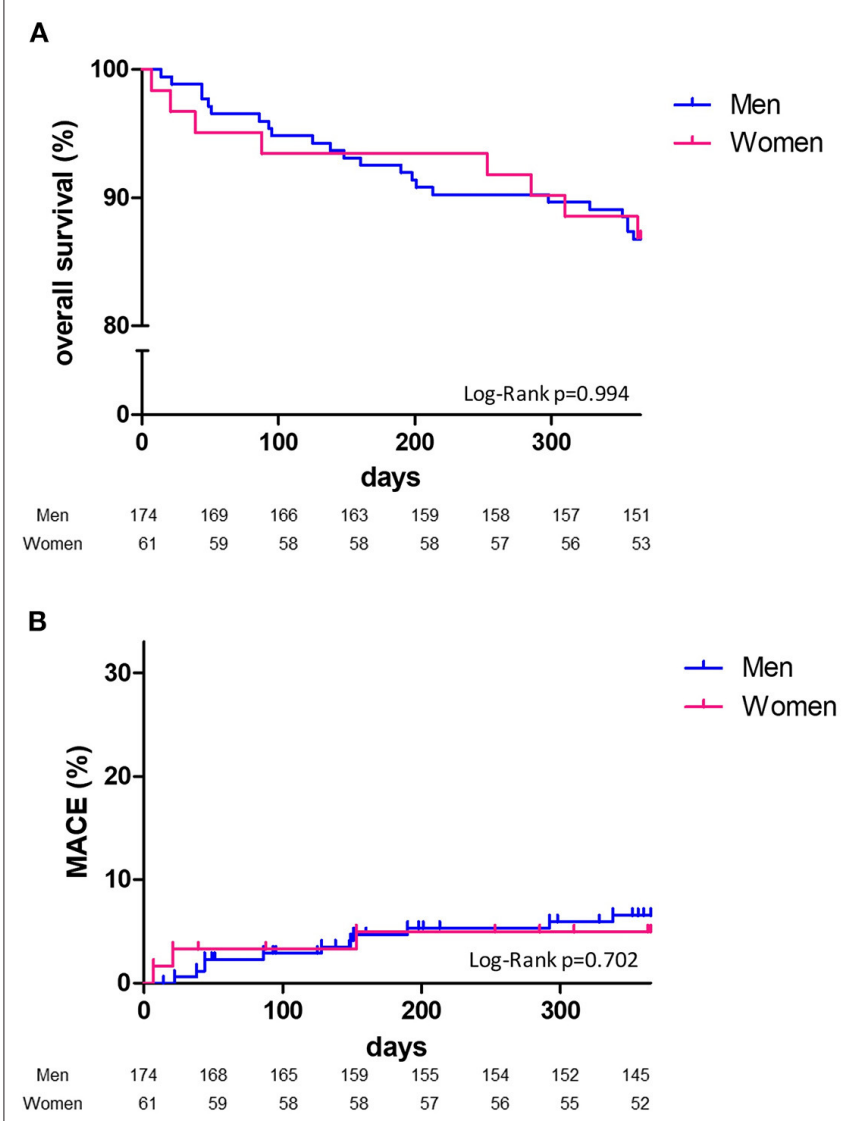

C

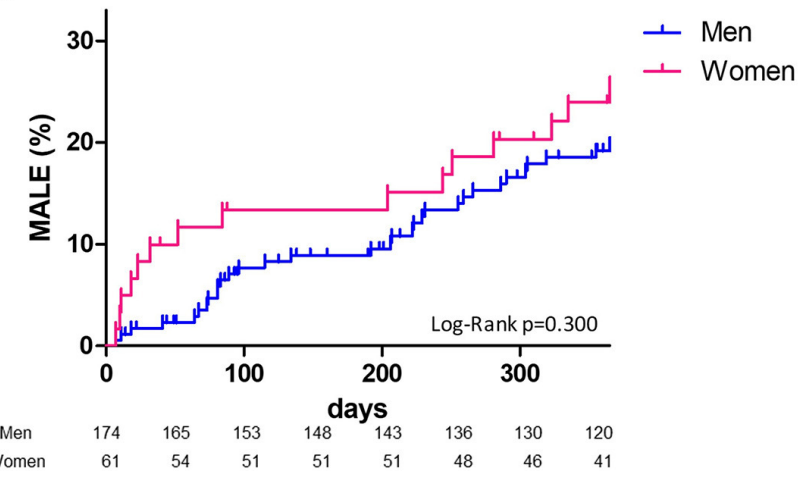

FIGURE 1 | One-year Kaplan-Meier survival curves. Overall survival (A), major adverse cardiovascular events: MACE (B), major adverse limb events: MALE (C) and comparison according to sex (men, blue line; women, red line) with Log Rank test comparisons between men (blue) and women (red).

on endothelial progenitor cells suggesting that gonadotropins blocking strategies could be a new interesting therapeutic approach in ASCVD (39).

Our study has some limitations. The limited number of patients included, and the short duration of follow-up make the power of this study insufficient to draw definitive conclusions. It may indeed underestimate the impact of sex on the 


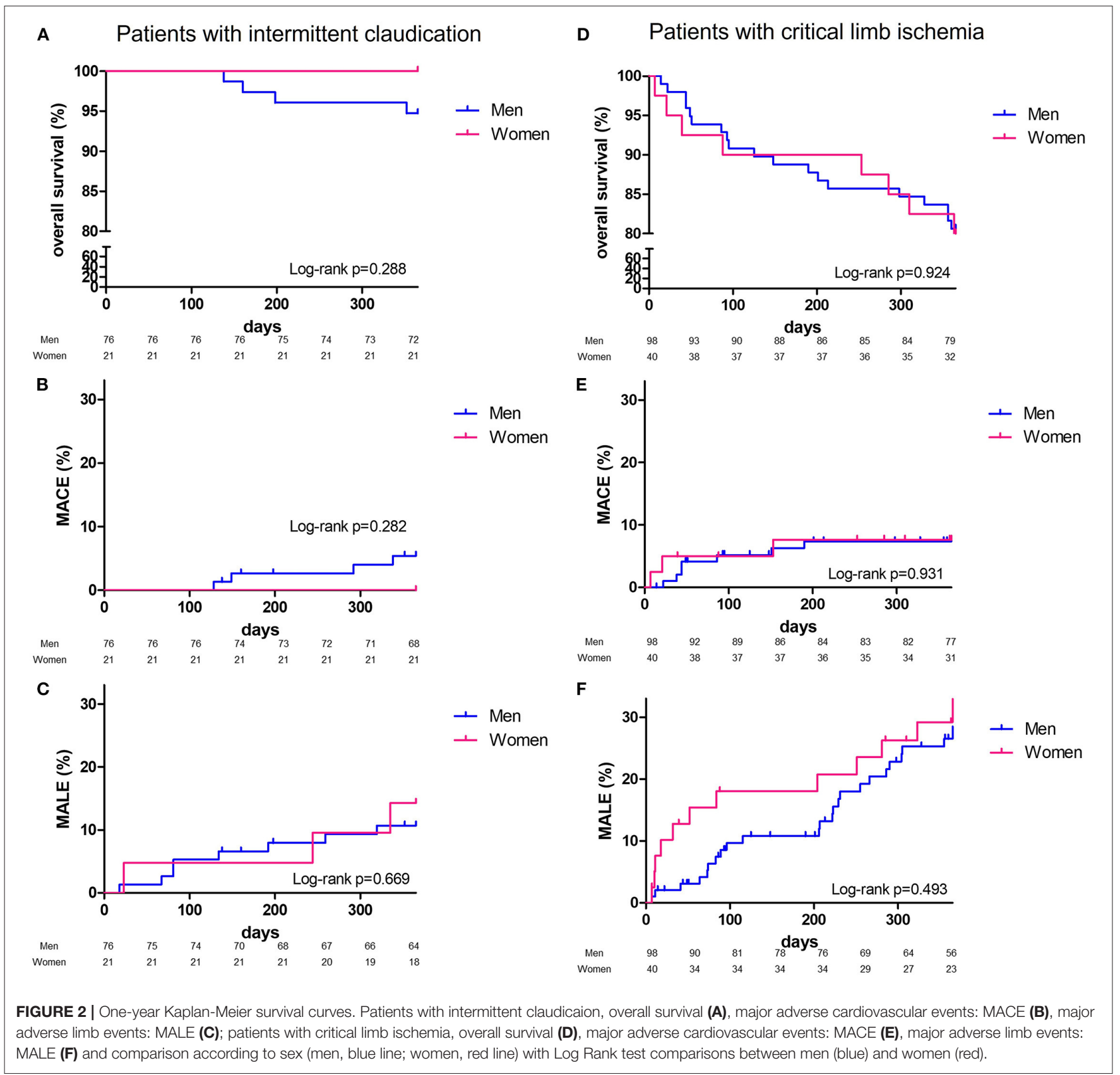

characteristics, management, and prognosis of PAD patients. Also, our study was not powered for detecting differences in terms of hard cardiac or limb events between men and women. Our findings should be addressed with usual caution and would require studies within larger registries to be confirmed. International registries like the RECCORD registry (40), able to collect and sum-up data from multiple tertiary and non-tertiary centers would be very useful to provide a comprehensive dataset depicting the current real life practice and outcome of vascular care (40). We cannot provide details for intermittent claudication staging. We do not perform indeed a Strandness walking test for the hospitalized patients to provide these data. However, the patients requiring hospitalization in our tertiary center are severely impacted by their walking-distance and most report a walking distance below $200 \mathrm{~m}$. However, the patients in our study shared the same cardiovascular risk factors and comorbidities than other PAD cohorts, where current smokers represented 16 to $39 \%$, hypertension 63 to $81 \%$, hyperlipidemia 57 to $67 \%$ and diabetes 26 to $44 \%$. Besides PAD, patients had coronary artery disease in 24 to $52 \%$ and cerebrovascular disease in 13 to $23 \%(22,41-45)$. Moreover, the accuracy of the data completion during follow-up was good as previously shown $(14,18,41,46)$. 
TABLE 3 | Baseline characteristics of patients dead within 1 year and sex comparison.

\begin{tabular}{|c|c|c|c|c|}
\hline & Total $(n=31)$ & Men $(n=23)$ & Women $(n=8)$ & $p$-value \\
\hline Median age at inclusion- years (IQR) & $80.0(69.5-86.1)$ & $76.2(69.2-81.9)$ & $87.6(80.1-92.3)$ & 0.02 \\
\hline \multicolumn{5}{|l|}{ Past-medical history at inclusion } \\
\hline Hypertension & $24(77.4)$ & $18(78.3)$ & $6(75.0)$ & 1.00 \\
\hline Hyperlipemia & $18(58.1)$ & $13(56.5)$ & $5(62.5)$ & 1.00 \\
\hline Smoking status & & & & 0.09 \\
\hline Never smoked & $12(38.7)$ & $6(26.1)$ & $6(75.0)$ & \\
\hline Current smoker & $6(19.4)$ & $6(26.1)$ & 0 & \\
\hline Former smoker & $13(41.9)$ & $11(47.8)$ & $2(25.0)$ & \\
\hline Diabete mellitus & 9 (61.3) & $15(65.2)$ & $4(50.0)$ & 0.76 \\
\hline Stroke & $4(12.9)$ & $1(4.3)$ & $3(37.5)$ & 0.04 \\
\hline Transient ischemic attack & 0 & 0 & 0 & 0 \\
\hline Coronary artery disease & $11(35.5)$ & $10(43.5)$ & $1(12.5)$ & 0.20 \\
\hline Myocardial infarction & $8(25.8)$ & $7(30.4)$ & $1(12.5)$ & 0.64 \\
\hline Heart failure & $5(16.1)$ & $4(17.4)$ & $1(12.5)$ & 1.00 \\
\hline Chronic obstructive pulmonary disease & $4(12.9)$ & $4(17.4)$ & 0 & 0.55 \\
\hline Abdominal aortic aneurysm & $2(6.5)$ & $2(8.7)$ & 0 & 1.00 \\
\hline Peripheral artery disease Rutherford category & & & & 0.27 \\
\hline Category 1/2/3 : Intermittent claudication & $4(12.9)$ & $4(17.4)$ & 0 & \\
\hline Category 4: Pain while at rest & $2(6.5)$ & $2(8.7)$ & 0 & \\
\hline Category 5/6 : Trophic lesion & $25(80.6)$ & $17(73.9)$ & $8(100)$ & \\
\hline Previous bypass revascularization & 7 (22.6) & $5(21.7)$ & $2(25.0)$ & 1.00 \\
\hline Previous endovascular revascularization & $13(41.9)$ & $11(47.8)$ & $2(25.0)$ & 0.41 \\
\hline Previous cardiovascular rehabilitation & $6(19.4)$ & $3(13.0)$ & $3(37.5)$ & 0.16 \\
\hline Previous lower limb amputation & $4(12.9)$ & $4(17.3)$ & 0 & \\
\hline Major amputation & $1(3.2)$ & $1(4.3)$ & 0 & 1.00 \\
\hline Minor amputation & $3(9.7)$ & $3(13.0)$ & 0 & 0.55 \\
\hline Revascularization before discharge & $30(96.8)$ & $22(95.7)$ & $8(100)$ & 1.00 \\
\hline
\end{tabular}

$I Q R$, interquartile range (25th - 75th percentile). Significant $p$ values are in bold.

\section{CONCLUSION}

We showed that overall mortality, cardiovascular outcomes, limb revascularization or amputation did not differ between men and women, 1 year after hospitalization for PAD in our tertiary center. Although the latter were older, less smoker and had less coronary artery disease. Due to the small size of this cohort, larger studies and future research are needed to better understand sex-specific mechanisms in the pathophysiology and natural history of PAD, including sex hormones and gonadotrophins changes over adult life.

\section{DATA AVAILABILITY STATEMENT}

The original contributions presented in the study are included in the article, further inquiries can be directed to the corresponding author.

\section{ETHICS STATEMENT}

The studies involving human participants were reviewed and approved by IRB CPP Sud Ouest et outre 79 mer II 0702108 . The patients provided their written informed consent to participate in this study. Written informed consent was obtained from the individual(s) for the publication of any potentially identifiable images or data included in this article.

\section{AUTHOR CONTRIBUTIONS}

TM, EM, and DS: conception and design. HM and EM: administrative support. GD, CC, AGa, GG, LK, JS, MS, PJ, and TM: provision of study materials or patients. $\mathrm{AGu}, \mathrm{NM}, \mathrm{OS}$, and $\mathrm{HM}$ : collection and assembly of data. AGu, GD, TM, DS, NG, and EM: data analysis and interpretation. All authors: manuscript writing and final approval of manuscript. 


\section{REFERENCES}

1. Vogel B, Acevedo M, Appelman Y, Bairey Merz CN, Chieffo A, Figtree GA, et al. The Lancet women and cardiovascular disease commission: reducing the global burden by 2030. Lancet. (2021) 397:2385-438. doi: 10.1016/S0140-6736(21)00684-X

2. Bots SH, Peters SAE, Woodward M. Sex differences in coronary heart disease and stroke mortality: a global assessment of the effect of ageing between 1980 and 2010. BMJ Glob Health. (2017) 2:e000298. doi: 10.1136/bmjgh-2017-000298

3. Peters SAE, Woodward M, Jha V, Kennedy S, Norton R. Women's health: a new global agenda. BMJ Glob Health. (2016) 1:e000080. doi: 10.1136/bmjgh-2016-000080

4. Pagidipati NJ, Peterson ED. Acute coronary syndromes in women and men. Nat Rev Cardiol. (2016) 13:471-80. doi: 10.1038/nrcardio.2016.89

5. Walli-Attaei M, Joseph P, Rosengren A, Chow CK, Rangarajan S, Lear SA, et al. Variations between women and men in risk factors, treatments, cardiovascular disease incidence, and death in 27 high-income, middle-income, and lowincome countries (PURE): a prospective cohort study. Lancet. (2020) 396:97109. doi: 10.1016/S0140-6736(20)30543-2

6. Hirsch AT, Allison MA, Gomes AS, Corriere MA, Duval S, Ershow AG, et al. A call to action: women and peripheral artery disease: a scientific statement from the American heart association. Circulation. (2012) 125:144972. doi: 10.1161/CIR.0b013e31824c39ba

7. Aboyans V, Ricco JB, Bartelink MLEL, Björck M, Brodmann M, Cohnert T, et al. 2017 ESC guidelines on the diagnosis and treatment of peripheral arterial diseases, in collaboration with the European society for vascular surgery (ESVS) Document covering atherosclerotic disease of extracranial carotid and vertebral, mesenteric, renal, upper and lower extremity arteries endorsed by: the European stroke organization (ESO) the task force for the diagnosis and treatment of peripheral arterial diseases of the European society of cardiology (ESC) and of the European society for vascular surgery (ESVS). Eur Heart J. (2018) 39:763-816. doi: 10.1093/eurheartj/ehx095

8. Hiatt WR, Fowkes FGR, Heizer G, Berger JS, Baumgartner I, Held P, et al. Ticagrelor vs. Clopidogrel in Symptomatic Peripheral Artery Disease. N Engl J Med. (2017) 376:32-40. doi: 10.1056/NEJMoa1611688

9. Anand SS, Bosch J, Eikelboom JW, Connolly SJ, Diaz R, Widimsky $\mathrm{P}$, et al. Rivaroxaban with or without aspirin in patients with stable peripheral or carotid artery disease: an international, randomised, double-blind, placebo-controlled trial. Lancet. (2018) 391:219-29. doi: 10.1016/S0140-6736(17)32409-1

10. Ankle brachial index combined with framingham risk score to predict cardiovascular events and mortality: a meta-analysis. JAMA. (2008) 300:197208. doi: 10.1001/jama.300.2.197

11. Amaranto DJ, Abbas F, Krantz S, Pearce WH, Wang E, Kibbe MR. An evaluation of gender and racial disparity in the decision to treat surgically arterial disease. J Vasc Surg. (2009) 50:1340-7. doi: 10.1016/j.jvs.2009.07.089

12. Feinglass J, McDermott MM, Foroohar M, Pearce WH. Gender differences in interventional management of peripheral vascular disease: evidence from a blood flow laboratory population. Ann Vasc Surg. (1994) 8:3439. doi: 10.1007/BF02132995

13. Desai R, Singh S, Fong HK, Goyal H, Gupta S, Zalavadia D, et al. Racial and sex disparities in resource utilization and outcomes of multi-vessel percutaneous coronary interventions (a 5-year nationwide evaluation in the United States). Cardiovasc Diagn Ther. (2019) 9:18-29. doi: 10.21037/cdt.2018.09.02

14. Cambou JP, Aboyans V, Constans J, Lacroix P, Dentans C, Bura A. Characteristics and outcome of patients hospitalised for lower extremity peripheral artery disease in France: the COPART registry. Eur J Vasc Endovasc Surg. (2010) 39:577-85. doi: 10.1016/j.ejvs.2010.02.009

15. Gerhard-Herman MD, Gornik HL, Barrett C, Barshes NR, Corriere MA, Drachman DE, et al. 2016 AHA/ACC guideline on the management of patients with lower extremity peripheral artery disease: executive summary: a report of the American college of cardiology/American heart association task force on clinical practice guidelines. Circulation. (2017) 135:e686725. doi: $10.1161 /$ CIR. 0000000000000470

16. Rieß HC, Debus ES, Heidemann F, Stoberock K, Grundmann RT, Behrendt CA. Gender differences in endovascular treatment of infrainguinal peripheral artery disease. Vasa. (2017) 46:296-303. doi: 10.1024/0301-1526/a000634
17. Ortmann J, Nüesch E, Traupe T, Diehm N, Baumgartner I. Gender is an independent risk factor for distribution pattern and lesion morphology in chronic critical limb ischemia. J Vasc Surg. (2012) 55:98-104. doi: 10.1016/j.jvs.2011.07.074

18. Pros N, Cambou JP, Aboyans V, Malloizel Delaunay J, Constans J, Lacroix $\mathrm{P}$, et al. Hospital discharge risk score for 1-year all-cause mortality or nonfatal cardiovascular events in patients with lower-extremity peripheral artery disease, with and without revascularisation. Eur J Vasc Endovasc Surg. (2013) 45:488-96. doi: 10.1016/j.ejvs.2013.01.034

19. Pâquet M, Pilon D, Tétrault JP, Carrier N. Protective vascular treatment of patients with peripheral arterial disease: guideline adherence according to year, age and gender. Can J Public Health. (2010) 101:96-100. doi: 10.1007/BF03405572

20. Feringa HHH, Karagiannis SE, van Waning VH, Boersma E, Schouten O, Bax JJ, et al. The effect of intensified lipid-lowering therapy on long-term prognosis in patients with peripheral arterial disease. J Vasc Surg. (2007) 45:936-43. doi: 10.1016/j.jvs.2007.01.024

21. Cacoub P, Cambou JP, Kownator S, Belliard JP, Beregi JP, Branchereau A, et al. Prevalence of peripheral arterial disease in high-risk patients using anklebrachial index in general practice: a cross-sectional study. Int J Clin Pract. (2009) 63:63-70. doi: 10.1111/j.1742-1241.2008.01953.x

22. Bhatt DL, Steg PG, Ohman EM, Hirsch AT, Ikeda Y, Mas JL, et al. International prevalence, recognition, and treatment of cardiovascular risk factors in outpatients with atherothrombosis. JAMA. (2006) 295:1809. doi: $10.1001 /$ jama.295.2.180

23. McDermott MM, Greenland P, Liu K, Criqui MH, Guralnik JM, Celic L, et al. Sex differences in peripheral arterial disease: leg symptoms and physical functioning. J Am Geriatr Soc. (2003) 51:222-8. doi: 10.1046/j.1532-5415.2003.51061.x

24. Sigvant B, Wiberg-Hedman K, Bergqvist D, Rolandsson O, Andersson B, Persson E, et al. population-based study of peripheral arterial disease prevalence with special focus on critical limb ischemia and sex differences. J Vasc Surg. (2007) 45:1185-91. doi: 10.1016/j.jvs.2007. 02.004

25. Vouyouka AG, Kent KC. Arterial vascular disease in women. J Vasc Surg. (2007) 46:1295-302. doi: 10.1016/j.jvs.2007.07.057

26. Jackson EA, Munir K, Schreiber T, Rubin JR, Cuff R, Gallagher KA, et al. Impact of sex on morbidity and mortality rates after lower extremity interventions for peripheral arterial disease. J Am Coll Cardiol. (2014) 63:2525-30. doi: 10.1016/j.jacc.2014.03.036

27. Malmstedt J, Leander K, Wahlberg E, Karlström L, Alfredsson L, Swedenborg J. Outcome after leg bypass surgery for critical limb ischemia is poor in patients with diabetes: a population-based cohort study. Diabetes Care. (2008) 31:887-92. doi: 10.2337/dc07-2424

28. Srivaratharajah K, Abramson BL. Women and peripheral arterial disease: a review of sex differences in epidemiology, clinical manifestations, and outcomes. Can J Cardiol. (2018) 34:356-61. doi: 10.1016/j.cjca.2018.01.009

29. Criqui MH, Aboyans V. Epidemiology of peripheral artery disease. Circ Res. (2015) 116:1509-26. doi: 10.1161/CIRCRESAHA.116.303849

30. Fowkes FGR, Aboyans V, Fowkes FJI, McDermott MM, Sampson UKA, Criqui MH. Peripheral artery disease: epidemiology and global perspectives. Nat Rev Cardiol. (2017) 14:156-70. doi: 10.1038/nrcardio.2016.179

31. Kannel WB, Hjortland MC, McNamara PM, Gordon T. Menopause and risk of cardiovascular disease: the Framingham study. Ann Intern Med. (1976) 85:447-52. doi: 10.7326/0003-4819-85-4-447

32. Nguyen L, Liles DR, Lin PH, Bush RL. Hormone replacement therapy and peripheral vascular disease in women. Vasc Endovasc Surg. (2004) 38:54756. doi: $10.1177 / 153857440403800609$

33. Janssen I, Powell LH, Crawford S, Lasley B, Sutton-Tyrrell K. Menopause and the metabolic syndrome. Arch Intern Med. (2008) 168:1568-75. doi: 10.1001/archinte.168.14.1568

34. Klein NA, Soules MR. Endocrine changes of the perimenopause. Clin Obstet Gynecol. (1998) 41:912-20. doi: 10.1097/00003081-199812000-00017

35. Sohrabji F, Okoreeh A, Panta A. Sex hormones and stroke: beyond estrogens. Horm Behav. (2019) 111:87-95. doi: 10.1016/j.yhbeh.2018.10.010

36. Munir JA, Wu H, Bauer K, Bindeman J, Byrd C, Feuerstein IM, et al. The perimenopausal atherosclerosis transition: relationships between calcified and non-calcified coronary, aortic, and carotid 
atherosclerosis and risk factors and hormone levels. Menopause. (2012) 19:10-5. doi: 10.1097/gme.0b013e318221bc8d

37. El Khoudary SR, Santoro N, Chen HY, Tepper PG, Brooks MM, Thurston $\mathrm{RC}$, et al. Trajectories of estradiol and follicle-stimulating hormone over the menopause transition and early markers of atherosclerosis after menopause. Eur J Prev Cardiol. (2016) 23:694-703. doi: 10.1177/2047487315607044

38. Zhu D, Li X, Macrae VE, Simoncini T, Fu X. Extragonadal effects of folliclestimulating hormone on osteoporosis and cardiovascular disease in women during menopausal transition. Trends Endocrinol Metab. (2018) 29:57180. doi: 10.1016/j.tem.2018.06.001

39. Détriché G, Gendron N, Philippe A, Gruest M, Billoir P, Rossi E, et al. Gonadotropins as novel active partners in vascular diseases: insight from angiogenic properties and thrombotic potential of endothelial colony-forming cells. J Thromb Haemost. (2022) 20:230-237. doi: 10.1111/jth.15549

40. M Malyar N, Stausberg J, Ito WD, Kölble H, Langhoff R, Lawall H, et al. Rationale and design of the recording courses of vascular diseases registry (RECCORD registry). VASA Z Gefasskrankheiten. (2017) 46:262267. doi: 10.1024/0301-1526/a000631

41. Mirault T, Galloula A, Cambou JP, Lacroix P, Aboyans V, Boulon C, et al. Impact of betablockers on general and local outcome in patients hospitalized for lower extremity peripheral artery disease: the COPART registry. Medicine. (2017) 96:e5916. doi: 10.1097/MD.0000000000005916

42. Steg PG, Bhatt DL, Wilson PWF, D'Agostino R, Ohman EM, Röther J, et al. One-year cardiovascular event rates in outpatients with atherothrombosis. JAMA. (2007) 297:1197-206. doi: 10.1001/jama.297. 11.1197

43. Blacher J, Cacoub P, Luizy F, Mourad JJ, Levesque H, Benelbaz J, et al. Peripheral arterial disease vs. other localizations of vascular disease: the ATTEST study. J Vasc Surg. (2006) 44:314-8. doi: 10.1016/j.jvs.2006. 04.002
44. Diehm C. Association of low ankle brachial index with high mortality in primary care. Eur Heart J. (2006) 27:1743-9. doi: 10.1093/eurheartj/ehl092

45. The PERART/ARTPER study group, Alzamora MT, Forés R, BaenaDíez JM, Pera G, Toran P, et al. The peripheral arterial disease study (PERART/ARTPER): prevalence and risk factors in the general population. BMC Public Health. (2010) 10:38. doi: 10.1186/1471-2458-10-38

46. Desormais I, Aboyans V, Bura A, Constans J, Cambou JP, Messas E, et al. Anemia, an independent predictive factor for amputation and mortality in patients hospitalized for peripheral artery disease. Eur J Vasc Endovasc Surg. (2014) 48:202-7. doi: 10.1016/j.ejvs.2014.04.005

Conflict of Interest: The authors declare that the research was conducted in the absence of any commercial or financial relationships that could be construed as a potential conflict of interest.

Publisher's Note: All claims expressed in this article are solely those of the authors and do not necessarily represent those of their affiliated organizations, or those of the publisher, the editors and the reviewers. Any product that may be evaluated in this article, or claim that may be made by its manufacturer, is not guaranteed or endorsed by the publisher.

Copyright @ 2022 Détriché, Guédon, Mohamedi, Sellami, Cheng, Galloula, Goudot, Khider, Mortelette, Sitruk, Gendron, Sapoval, Julia, Smadja, Mirault and Messas. This is an open-access article distributed under the terms of the Creative Commons Attribution License (CC BY). The use, distribution or reproduction in other forums is permitted, provided the original author(s) and the copyright owner(s) are credited and that the original publication in this journal is cited, in accordance with accepted academic practice. No use, distribution or reproduction is permitted which does not comply with these terms. 